\title{
ESCOLARIZAÇÃO E DEFICIÊNCIA INTELECTUAL: ENTRE OTIMISMOS E FRUSTRAÇÕES
}

\author{
INTELLECTUAL DISABILITY AND SCHOOLING:BETWEEN OPTIMISM \\ AND FRUSTRATION
}

\author{
ESCOLORIZACIÓN Y DISCAPACIDAD INTELECTUAL: ENTRE EL \\ OPTINISMO Y LAS FRUSTRACIONES
}

\author{
Renata da Silva Andrade Sobral \\ E-mail: renata.sas2016@gmail.com \\ Amelia Araujo Mesquita \\ E-mail: amelia.mesquita05@gmail.com \\ Universidade Federal do Pará - UFPA
}

\begin{abstract}
RESUMO
O presente artigo discute a escolarização de um aluno deficiente intelectual que concluiu a educação básica em escolas públicas do estado do Pará. Num contexto onde o índice de alunos com deficiência que concluem a educação básica ainda é muito escasso. A pesquisa teve por objetivo analisar como se constituiu a trajetória de escolarização de um aluno com Deficiente Intelectual que concluiu a educação básica no Estado do Pará, esta se desenvolveu numa abordagem qualitativa, por meio da memória individual de um sujeito com deficiência intelectual. Os dados são oriundos da entrevista semiestruturada e da análise documental, e foram tratados por meio da análise de conteúdo. Como resultado, identificamos que a escolarização do sujeito da pesquisa foi produzida na experiência entre os modelos integrativo e inclusivo, inclusive com forte demarcação institucional. No entanto, independente do modelo, em ambos os casos a escola reforçou estigmas que limitaram a capacidade de aprendizagem desse aluno. Os vinte seis anos que constituíram seu tempo de escolarização, revelam expectativas e frustações, reforçando a ideia de que o objetivo da escola deve ir além da contribuição no desenvolvimento de capacidades cognitivas, no entanto potencializar todas as capacidades do ser humano.
\end{abstract}

PALAVRAS-CHAVE: Trajetória de Escolarização. Deficiência Intelectual. Escola.

\section{ABSTRACT}

This article discusses the schooling of an intellectual deficient student who completed basic education in public schools in the state of Pará. In a context where the index of students with disabilities who complete basic education is still very scarce. The objective of the research was to analyze how the education path of a student with intellectual deficiency who completed basic education in the state of Pará was constituted, this one developed in a qualitative approach, through the individual memory of a subject with intelectual disability. The data come from the semi-structured interview and the documentary analysis, and were treated through content analysis. As a result, we indentified that the subject's schooling was produced in the experience between integrative and inclusive models, even with Strong institutional demarcation however, regardless of the model, in both cases the school reinforced stigmas capacity that limited that student's learning. Twenty-six years that constituted their school time reveal expectations and reinforce the idea that the school's goal is to contribute to cognitive abilities, but to enhance all human abilities.

KEYWORDS: Trajectory of schooling. Intellectual disability. School. 


\section{RESUMEN}

El presente articulo discute la escolarización de un alumno deficiente intelectual que concluyó la educación básica en escuelas públicas del estado de Pará. En un contexto donde el índice de alumnos con discapacidad que concluye educación básica todavía es muy escaso.La investigación tuvo por objetivo analizar cómo se constituyó la trayectoria escolarización de um alumno com Deficiente Intelectual que concluyó la educación básica em el Estado de Pará, ésta se desarrolló em um abordaje cualitativo, por médio de la memoria individual de un sujeto con discapacidad intelectual los datos oriundos de la entrevista semiestruturada y del análisis documental, y fueron tratados por médio del análisis de contenido. Como resultado, identificamos que la escolaridade del sujeto de la investigación fue producida en la experiência entre los modelos integrativo e inclusivo, incluso con fuerte demarcación institucional. Sin embargo, independentemente del modelo, en ambos casos la escuela reforzó que limitaron la de aprendizaje de ese alumno. Seis años que constituyeron su tiempo escolar, revelan expectativas y reforzando la ideia de que la escuela debe ir más allá de la contribución en el desarrollo de capacidades cognitivas, sin embargo potenciar todas las capacidades del ser humano.

PALABRAS-CLAVE: Trayectoria de Escolarización. Deficiencia Intelectual. Escuela

\section{INTRODUÇÃO}

O presente texto é parte da pesquisa de Mestrado em Educação, cujo objetivo principal foi analisar como se constituiu a trajetória de escolarização de um aluno com Deficiência Intelectual que concluiu a educação básica no Estado do Pará.

A preocupação em ouvir estes sujeitos gerou aproximação com o objeto de estudo "Trajetória de escolarização de um aluno com deficiência intelectual na Educação Básica". Conhecer a trajetória de um indivíduo que passou por todas as etapas deste nível de ensinoeducação infantil, ensino fundamental e médio - contribuiu para conhecer os desafios e superações do percurso escolar de uma pessoa com deficiência intelectual na educação básica.

É oportuno refletir que a "recente" inclusão das pessoas com deficiência intelectual nos leva ao crescente quantitativo desses discentes que tem avançado para os anos finais do ensino fundamental e ensino médio, ainda que os dados não sejam muito significativos. Essa caminhada mesmo que pequena, revela muitos obstáculos que surgiram ou irão surgir na trajetória escolar destes educandos, sendo fundamental estudos que identifiquem o avanço ainda tímido para as etapas finais da educação básica.

Nesse contexto, ressalto a importância de revelar trajetórias escolares individualizadas e diferenciadas, considerando possível, além de imprescindível, permitir ao aluno com deficiência intelectual o avanço em seu processo educacional e que, ao longo de seu percurso, estabeleça novas possibilidades de formação. 
A igualdade de direitos para frequentar a escola transformou-se em realidade, no entanto, mesmo com as transições que ocorreram para se chegar a esta "universalização", muitos são os desafios para atender esta demanda no contexto das salas de aula, com destaque para a deficiência intelectual, que é uma das deficiências mais recorrentes entre as matrículas nas instituições públicas. Compreendo que passar a palavra para o deficiente intelectual, a fim de lhe possibilitar reconstruir a sua própria trajetória escolar, possibilita escutar a sua versão sobre as experiências vividas ao longo dessa trajetória.

\section{REFERENCIAL TEÓRICO}

\subsection{Inclusão e Escolarização}

Educação e instrução nem sempre estiveram atrelados ao espaço formal da escola, pois, o significado atribuído à educação é bem mais amplo que o próprio conceito de escola. Mesmo antes dos sistemas escolares as gerações já se educavam. No entanto, com o passar do tempo e à medida que as sociedades vão se modificando, a educação passa a ser formalizada por meio da escolarização. Então acredito ser necessário esclarecer o que é escolarização. Segundo Baptista, escolarização é:

[...] O complexo processo que envolve aspectos relacionados com a instituição escolar: a quem é oferecida, qual a sua função, sua organização, seu currículo, a tecnologia a sua disposição (livros, recursos e materiais utilizados para a escrita, entre outros), a forma e o princípio das ações pedagógicas desenvolvidas em seu interior, o sistema escolar (se é constituído ou não), entre outros, inclui os saberes culturais associados a determinados grupos profissionais e a transformação destes em disciplinas escolares.(2015,p.53)

Penso que o autor compreende a escolarização como uma instituição organizada, com conhecimentos definidos e práticas escolares pré-estabelecidas, uma escola configurada para dar conta de atender determinados sujeitos. A escola com sua possível provisoriedade, alicerçou-se em processos de escolarização que se estabeleceram por meios não democráticos, excludentes e segregadores de grupos menos privilegiados, incluindo aí os alunos com deficiência.

No entanto, esse cenário sofre alterações através de mobilizações sociais e do fenômeno da urbanização, ligadas as transformações ocorridas mundialmente, inicia-se um processo de ampliação da participação, tornando-se um fator essencial para o 


\section{Revista Triângulo}

desenvolvimento social, na perspectiva de constituir sujeitos para o prosseguimento de estudos, pelo menos a nível legal. Como afirmam Bueno, Mendes e Santos (2008, p.28):

[...] os processos de ampliação de oportunidades de acesso à escola pública, redundou, na atualidade, na quase universalização absoluta de acesso a esse nível de ensino, foram acompanhados por um forte comprometimento da sua qualidade, especialmente em razão de políticas públicas que pouco privilegiam esse aspecto.

Nesse processo de ampliação de oportunidades o paradigma inclusivo se favorece principalmente a partir da década de 1990, ganhando possibilidades reais de se efetivar. O encontro entre inclusão e escolarização no ensino regular, representa uma inovação para um país que, por séculos, negou, de modo elitista e seletivo, aos excluídos o direito ao conhecimento da escola sistemática e regular. ${ }^{1}$

Penso que são necessários ajustes nos processos atuais de escolarização para que a inclusão se efetive de fato, e paralelamente, perceber que esta "progressiva universalização" é recente em nossa sociedade. E a atual progressão dos alunos com deficiência para as etapas superiores, lançam novas dificuldades que são percebidas para sua permanência e sucesso escolar.

Por fim, acredito que essa nova perspectiva de educação que "inclui e escolariza todos" necessita ir além da educação formal, se estendendo ao longo da vida desse sujeito e contribuindo com a ruptura do conceito homogeneizador, constatando que a escolarização deve propiciar um aprendizado que leve a outros contextos sociais.

\subsection{Escolarização de pessoas com Deficiência Intelectual}

O reconhecimento da educabilidade da pessoa com deficiência intelectual se construiu gradativamente, as concepções sociais e políticas se modificaram até se chegar à ideia, de que a deficiência não retira do homem a sua possibilidade de aprendizagem. As ideias de escolarização dos sujeitos com deficiência intelectual ganham força quando a sociedade abandona a ideia de culpabilização do indivíduo pela própria deficiência, suas visões supersticiosas de não aceitação da condição humana ou tendo-a como um fato de má sorte pessoal.

\footnotetext{
${ }^{1}$ Vale ressaltar que a política de inclusão apresenta finalidades e se constituiu como parte da política neoliberal.
} 
A pessoa com deficiência passa a ser vista, na segunda metade do século XVIII, como um indivíduo bom, diferente de outrora. No entanto, é a partir do século XIX, através do trabalho do médico Jean Itard (1774-1838), com o menino Victor de Aveyron, que as pessoas com deficiência intelectual foram consideradas passíveis de serem educadas. Vale ressaltar, que apesar do pouco reconhecimento e notoriedade de seu trabalho nas obras brasileiras, a contribuição de Édouard Sèguin (1812-1880) seguidor de Itard, foi de grande aporte para a educação destes sujeitos. Atuou na crítica à prevalência da visão médica de incurabilidade da deficiência. Seu trabalho influenciou outros importantes teóricos, com destaque para Montessori (1870-1925), teórica que se inclinou na educação do deficiente intelectual.

Os esforços por parte de Itard e Séguin, mais tarde, influenciariam o trabalho de Maria Montessori (1870-1952). Compreendo que esses teóricos foram fundamentais para que a escolarização desses indivíduos fosse possível e para um olhar além do viés terapêutico. Eles inauguram um período de questionamento de novas formas de pensar a educabilidade do deficiente intelectual, para além do modelo médico, que vai florescendo no século XX.

A nova concepção era de que o deficiente poderia aprender. Segundo Antunes (2012), mesmo diante das descobertas de Itard, Séguin e outros, as concepções sobre o desenvolvimento das pessoas com deficiência intelectual ainda eram fortemente baseadas nos diagnósticos médicos. A visão clínica da deficiência foi assimilada por outras áreas do conhecimento, como a psicologia, por exemplo, com os conhecidos testes de QI (Quociente de Inteligência).

A inclusão enquanto acolhimento de novos sujeitos no contexto escolar, constituiu-se um passo importantíssimo para todas as deficiências. Por outro lado, ainda que o "acolhimento" tenha sido um passo importante para a possível quebra de paradigmas, ela não foi e não é suficiente para impor uma nova dinâmica ao processo de escolarização de alunos com deficiência. No caso específico da deficiência intelectual, a escolarização desses alunos na educação básica é marcada por uma série de elementos que qualificam positiva ou negativamente a estada desses sujeitos na escola, conforme podemos observar no subtópico a seguir. 


\subsection{Escolarização e Deficiência Intelectual na Educação Básica: O que mostram as pesquisas?}

As reflexões aqui apresentadas trazem pesquisas que abordam reflexos sobre a escolarização de alunos com deficiência intelectual na Educação Básica, considerando que a educação Básica é um nível ensino constituído por três etapas: educação infantil, ensino fundamental e ensino médio. E que esta foi oficialmente instituída no Brasil em 1996 com a promulgação da Lei de Diretrizes e Bases da Educação Nacional (9394/96). De forma transversal, a educação básica é composta por diferentes modalidades, entre elas a educação especial. Vale destacar que de acordo com a LDB (9394/1996) no seu artigo 22, a Educação Básica tem como finalidade desenvolver o educando, assegurar-lhe a formação comum indispensável para o exercício da cidadania e fornecer-lhe meios para progredir no trabalho e em estudos posteriores, no entanto, a realidade das escolas ainda revela dificuldades para garantir o seu efetivo desenvolvimento.

De acordo com as pesquisas que tratam sobre a escolarização dos alunos com deficiência intelectual na educação básica, observei que a literatura veem demonstrando a necessidade de se pensar três questões fundamentais: 1) a formação inicial/continuada de professores; 2) a necessidade de adequações/ flexibilizações curriculares e; 3) a crítica a falta de acesso aos conhecimentos escolares.

Sobre a formação inicial e continuada, Antunes (2012) e Santos (2012) ao pesquisar sobre as práticas de professores frente à deficiência intelectual, vai ao encontro de tais pesquisas, ao afirmar que muitas das dificuldades situadas pelos docentes e observadas no cotidiano escolar têm origem nas lacunas presentes na sua formação. Embora os autores acreditem que não existam "receitas" a serem seguidas, tal formação, se bem desenvolvida, contribuirá para uma mudança das práticas referentes ao ensino no contexto da escola.

Contudo pesquisas mais recentes como Pletsch, Oliveira, Araujo (2015) e Pletsch, Araújo e Lima (2017) chamam atenção para o fato de que ainda há um impasse historicamente constituído sobre a formação do professor especialista e generalista. Visto que, ainda hoje ocorre escassez de profissionais com formação específica em Educação Especial, e que há professores atuantes no atendimento educacional especializado que não possuem nenhuma formação em educação especial ou educação inclusiva, o que implica diretamente na escolarização dos alunos com deficiência. 
A educação especial na perspectiva inclusiva requer mudanças que visem o incentivo das adaptações/flexibilizações curriculares, já que Fantacini e Dias (2015) notaram que as falas dos professores chamam a atenção para o fato de que em seus cursos de formação específica praticamente não havia uma formação adequada para a implementação de adaptações/flexibilizações curriculares. Devido a isso, concluiu que as adequações curriculares realizadas aconteciam de forma espontânea, sem planejamento prévio. Tais constatações foram feitas durante as entrevistas, conforme os sujeitos iam exteriorizando em suas falas as dificuldades para desenvolvê-las. Outra conclusão é que embora a escola tenha disponível material pedagógico e tecnológico, estes não são utilizados com muita frequência, caso fossem mais trabalhados, o referido material poderia contribuir bastante para a aprendizagem dos alunos dessas turmas investigadas.

Pletsch, Oliveira e Araújo (2015) concluíram em sua pesquisa que em grande medida, esses alunos, apesar da garantia da matrícula, continuam não tendo acesso aos conhecimentos escolares que garantam o seu efetivo desenvolvimento. Também ficou evidente que muitos dos alunos com essa deficiência, por não terem sido alfabetizados, acabam sendo encaminhados para classes de Educação de Jovens e Adultos (EJA). Antunes (2012) já havia apresentado dado parecido, e acredita que a resposta para tal situação seria o professor olhar para o aluno e reconhecer as suas possibilidades de aprendizagem e a partir daí iniciar uma proposta de intervenção pedagógica que valorize e explore o potencial desses alunos. Neste caso o diagnóstico da deficiência deixa de ser um aspecto limitador e passa a ser mais uma ferramenta que possibilita ao professor conhecer melhor a condição do aluno para, então, realizar seu trabalho.

Compreendo que dentre as variáveis citadas, uma não deixa de ser consequência da outra, $\log o$ a precarização na formação de professores leva a falta de adequações/flexibilizações curriculares, ou seja, investir na formação continuada de professores, com foco nas adaptações/flexibilizações curriculares e no ensino colaborativo, a fim de efetivar o processo de ensino aprendizagem do aluno com deficiência intelectual. Visto que, questionar a aprendizagem do aluno implica em refletir sobre o trabalho que o professor realiza. Para isso, concordo com Antunes (2012) tornar o ensino mais dialógico é um caminho importante para fazer com que a relação entre professor e aluno seja pautada na troca e não de transmissão unilateral dos conteúdos. 


\section{MATERIAIS E MÉTODOS}

Ao enveredar pelo objeto de estudo, visando alcançar os objetivos propostos, erigi uma trajetória metodológica onde ancoraremos o percurso metodológico na abordagem qualitativa. Segundo Creswell (2007), a pesquisa qualitativa usa de métodos que interagem com o ser humano, envolvendo os participantes na coleta de dados estabelecendo uma harmonia e credibilidade com as pessoas no estudo, concentrando em único fenômeno de pesquisa, identificar os sujeitos participantes, o locus de pesquisa, a funcionalidade do estudo, ressaltando não uma rigidez estabelecida, mas a tentativa de desenvolver um estudo embasado nas informações recebidas dos participantes. A escolha do paradigma qualitativo me possibilita enquanto pesquisadora compreender seus pensamentos e toda a complexidade que envolve as relações sociais estabelecidas por este indivíduo no seu percurso escolar, obtendo a maior compreensão de sua trajetória, além da interação com o sujeito pesquisado.

Penso que este método é o mais adequado ao fenômeno a ser pesquisado por objetivar analisar através da memória individual o que a escola proporcionou para o aluno com deficiência intelectual durante seu processo educativo, pois, de acordo Halbwachs (1990) cada memória individual é um ponto de vista sobre a memória coletiva, que este ponto de vista muda conforme o lugar que ali se ocupa, e que este lugar mesmo muda segundo as relações que se mantêm com outros meios. Nesse sentido, torna-se ímpar conhecer a memória individual a partir do ponto de vista do aluno que acaba sendo exceção. Por consequência, perceber até que ponto esta memória foi socialmente construída, como afirma o autor, à vista disso, se seu posicionamento reflete as transições inevitáveis ocorridas durante sua trajetória escolar

\subsection{O movimento da pesquisa exploratória e a definição do sujeito da pesquisa}

Motivada pela escassez de pesquisas deste viés, iniciei o processo de buscas por um aluno com deficiência intelectual que tivesse concluído a Educação Básica, visando desenvolver a pesquisa baseada em sua trajetória escolar, já que estes indivíduos, ainda hoje, apresentam dificuldades durante a escolarização e de ingresso no ensino superior.

Diante dessa situação e sabendo, pelos dados do senso, que existem alunos com deficiência intelectual no estado do Pará que concluíram a educação básica, busquei

\begin{tabular}{l|l|l|l|l|l|l|} 
(C) Rev. Triang. & Uberaba, MG & v.11 & n.3 & p. 139-158 & Set. / Dez. & 2018 \\
\hline
\end{tabular}




\section{Revista Triângulo}

identificar esse sujeito nas próprias escolas de educação básica. O levantamento junto a Coordenação de Educação Especial, indicou uma escola. Ao conversar com a direção desta escola, ouvi alguns relatos de alunos com deficiência intelectual que lá haviam concluído, dentre eles, um em especial foi lembrado pela equipe pedagógica com muito saudosismo, por ser participativo e muito agradável com todos. Ao entrar em contato, ele se disponibilizou a conversar.

Ao conhecer um pouco mais sobre este aluno, descobri que tinha passado por 4 (quatro) escolas no decorrer de sua trajetória escolar na educação básica, inclusive por classes especiais, escolas especializadas, até finalmente concluir a educação básica em uma escola regular. A partir do relato de todos os obstáculos que estiveram presentes em seu percurso, e baseado nas baixas estatísticas de permanência deste coletivo de alunos nos níveis mais avançados da educação básica, os critérios para a definição do sujeito da pesquisa foram se modificando no decorrer do processo.

Com a redefinição dos critérios para escolha do sujeito, a opção foi trabalhar com um único aluno deficiente intelectual, como sujeito da pesquisa.

\section{ANÁLISE DOS DADOS E RESULTADOS}

O início da vida escolar de JC foi em 1985, aos 5 anos de idade, em uma turma regular, já que o aluno até então, não possuía o diagnóstico de pessoa com deficiência intelectual, no ano seguinte cursou a alfabetização. Em 1987, aos 7 anos, ingressou na $1^{\text {a }}$ série, ficou nesta até 1989 (dos 7 aos 9 anos). Segundo consta em seus pareceres, no aspecto relacionado à escolarização:

[...]. Iniciou com 5 anos no pré-escolar-jardim. Com 6 anos fez alfabetização e com 7 anos foi para a $1^{a}$ série, onde está com tri-repetência. (Parecer sobre JC-preenchido em 1990, grifo nosso)

A ênfase na leitura e escrita direciona as memórias de JC, colaborando com a abordagem conteudista, esta se faz presente durante os anos iniciais da escolarização do aluno, principalmente quando atribui o fato de não ter adquirido a leitura ao seu insucesso na $1^{\mathrm{a}}$ série do ensino fundamental, conforme o relato abaixo.

[...] não sabia ler, todo mundo já sabia e eu nada. Todo mundo aprendia

..." (Relato de JC-sobre a escola na qual cursou a primeira série do ensino fundamental) 
A escolarização como foi traçada historicamente baseada na homogeneização dos alunos pouco contribuiu para que JC pudesse vivenciar alguma experiência de sucesso escolar, adverso a isso, agravou a descrença sobre sua capacidade de aprender. Este modelo de ensino não gera as mesmas condições de aprendizagem para todos os alunos, evidente no caso de JC, que inicia uma história de retenções na $1^{\mathrm{a}}$ série do ensino fundamental.

Principalmente por estimular um modelo de enfoque enciclopédico cuja aplicação dos conteúdos está relacionada à utilização/leitura do livro didático, onde a ação dos alunos é não participativa, ocorre a repetição de exercícios. Sobre a utilização do livro didático, quando se utiliza somente este material pedagógico, o livro acaba sendo o roteiro das aulas, fato que compromete a aprendizagem, pois tal postura, acaba por não considerar as diversidades do alunado, além de não despertar a curiosidade e seu interesse. $\mathrm{O}$ que foi registado no depoimento de JC é que o livro didático em algumas situações é apresentado como única fonte para direcionar o processo de ensino-aprendizagem, conforme abaixo:

[...] tinha que ler o livro que levava pra casa, e caderno também, mas a professora não entendia o que eu escrevia..." (Relato de JC-sobre a escola na qual cursou a primeira série do ensino fundamental)

Entendo a importância do livro didático e que este deve ser visto como um dos instrumentos de apoio necessário ao trabalho pedagógico, não como único. Caso contrário colabora para acrescer as dificuldades, como ocorreu com JC, onde a escola parece pouco contribuir em seu processo de ensino-aprendizagem, ao contrário, ele próprio vai incorporando a perspectiva de impossibilidade, imputando somente a si o fracasso escolar. $\mathrm{O}$ desenho que se constrói deste período está baseado na abordagem tradicional, na transmissão verbal de conceitos e memorização mecânica, com uma visão simplificadora do ensino, do professor e de sua formação (LANGHI E NARDI, 2011).

\subsection{A Vivência na educação especial: entre a classe e a escola especial (Contexto 1990- 2002)}

A trajetória de JC continua, quando em 1990 (com 10 anos, após 3 anos frequentando a $1^{\mathrm{a}}$ série) foi transferido para a classe especial. O encaminhamento para a classe foi realizado 
a partir da aplicação de testes de inteligência. Esta organização foi utilizada por Antipoff ${ }^{2}$ na década de 1930, e acabou deixando resquícios durante boa parte do século XX, que reverberaram na trajetória de JC na década de 1990, inclusive os motivos que levam o encaminhamento de JC a classe especial, refere-se as retenções e ao resultado em 3 (três) testes de inteligência, nos quais, o aluno apresentou resultados abaixo do esperado para sua idade.

Ao descobrir mais sobre a avaliação de JC na classe especial, ficou evidente que o aluno ao invés de tentar compreender as atividades propostas, acabava demonstrando o posicionamento de quem não queria fazer, quando na verdade não sabia fazer. Conforme, apresento no trecho citado:

[...] Fazia prova as vezes, quando não entendia desistia de fazer, a professora deixava. O dever também, fazia quando era fácil. (Relato de JC ao ser questionado se realizava trabalhos ou provas na classe).

Penso que a avaliação esta deve proporcionar a emancipação do aluno com deficiência; o educando deve ser capaz de dizer o que aprendeu, o que acha interessante estudar e como o conhecimento modifica sua vida. A função da avaliação não é medir se o aluno chegou a determinado ponto, mas se ele cresceu, e se está aos poucos vencendo suas limitações (AIMI; TAMBORIL, 2011). Adverso ao que prega as autoras é a situação vivida por JC durante o tempo que permaneceu na classe especial. $\mathrm{O}$ aluno realizava as atividades quando acreditava ser interessante, ou quando acreditava ser possível realizar, ou seja, quando the parecia "fácil", contribuindo com a ideia de impossibilidade acentuada pela escola durante o período na educação especial.

Além de que os "métodos, técnicas e recursos pedagógicos especializados", nem sempre faziam parte do currículo destinado a esses alunos, conforme o relato de JC.

[...] Eu fazia limpeza do quadro, ventilador, limpava o colégio, varria as folhas e brincava com jogo. (Relato de JC)

\footnotetext{
${ }^{2}$ Educadora e psicóloga russa, foi convidada pelo governo de Minas Gerais, para ensinar Psicologia a professores e técnicos em educação.
} 
Neste depoimento, deixa claro o que realizava como aluno da classe especial. Percebido como inapto para a aprendizagem escolar ajudava na limpeza da escola, contribuindo para a permanência do processo de exclusão que continuava e se intensificar na classe especial. O conhecimento proporcionado para JC na classe especial visava a aquisição de conteúdos simples e se reduzia a atividades cotidianas da sala de aula, com ênfase em desenhos, pintura, pontilhados e tracejados.

\subsection{O ingresso na instituição especializada}

A trajetória de JC continua quando ingressa em um outro modelo integrativo no ano de 1998 (quando possuía 18 anos), é matriculado em uma instituição estadual especializada em alunos com deficiência intelectual, permanecendo até o fim do ano de 2002 (quando possuía 22 anos). JC foi encaminhado para a instituição especializada em deficientes intelectuais, pois, no entendimento dos professores da classe ele necessitava aprender ofícios, como mostra seu parecer:

Diante do que foi trabalhado no decorrer do tempo em que cursou a classe especial DM, onde superou algumas dificuldades, sou favorável o seu ingresso na Unidade Especializada para que possa realizar-se profissionalmente. (Trecho da ficha de evolução do aluno-preenchido pela professora da classe especial-2002).

Além da profissionalização que ofertava oficinas de panificação, sapataria, jardinagem, entre outros, o aluno ainda teria acesso a atendimentos clínicos, como: fonoaudiologia, psicologia e assistência social. Portanto, nessas instituições o atendimento prioritário era o profissionalizante e o da área da saúde, em detrimento do educacional. Ou seja, JC foi submetido a uma série de atendimentos com pouca ou nenhuma relação com o currículo escolar, aspectos como o comportamento e sua tolerância ao participar das atividades da instituição ganhavam mais ênfase do que o aspecto educacional.

O trabalho da instituição especializada seguiu distanciado do que deveria ser ofertado em uma escola regular, durante os quatro anos em que permaneceu frequentando apenas esta instituição. Não houve espaços de reflexão conjunta sobre o ensino do aluno com defíciência intelectual e, ainda, o trabalho com o conhecimento e o currículo escolar não foi priorizado, até porque esta não tinha caráter de escolarização. 
Entendo que no contexto do final da década de 1990, período em que JC ingressou neste modelo educacional, essas instituições já necessitavam de adequações e de ressignificação, fato que ganhou destaque no paradigma da educação inclusiva, sobretudo em relação às finalidades, currículos e práticas para superar o caráter assistencialista e garantir o apoio pedagógico aos alunos com deficiência, visando promover o desenvolvimento da autonomia, independência, inclusão social e aprendizagem acadêmica.

A permanência no modelo integrativo de JC, entre a classe especial e as instituições especializadas, perdurou 12 anos (dos 10 aos 22 anos de idade). A meu ver as políticas próinclusão que surgiram durante os anos 1990 influenciaram na transferência deste aluno para o ensino regular. Mesmo com estas dificuldades evidenciadas na trajetória escolar do aluno, não constituíram impedimentos para que permanecesse estudando e posteriormente acabasse migrando para outro modelo de escolarização.

\subsection{O contexto de reingresso na escola regular}

O retorno de JC à escola regular se deu no ano de 2003, aos 23 anos, motivado pela diretora da escola especializada. Seu retorno constitui-se necessariamente no reinicio da escolarização desde o $1^{\circ}$ ano do ensino fundamental, organizado da seguinte forma: Em 2003 realiza a $1^{\mathrm{a}}$ etapa e no ano seguinte sofre uma retenção, permanecendo dois anos seguidos nesta etapa. Em 2005 conclui a $2^{\mathrm{a}}$ etapa e segue sua escolarização em séries, $5^{\mathrm{a}}, 6^{\mathrm{a}}, 7^{\mathrm{a}}$ e $8^{\mathrm{a}}$ série concluindo o ensino fundamental em 2009. Inicia o Ensino Médio em 2010: $1^{\mathrm{a}}$ ano e $2^{\mathrm{a}}$ etapa ( $2^{\circ}$ e $3^{\circ}$ ano), concluindo a educação básica em 2011.

A percepção de JC acerca do ingresso na escola regular, representa uma fase de grande expectativa em relação a essa escola, de muitas descobertas, acompanhadas do seu desejo de pertencer a essa instituição. Usar os artefatos, viver a rotina espaço/tempo, se relacionar com os sujeitos são elementos que constituíam otimismo para o aluno.

JC relembra como foi tecendo sua experiência na escola regular, demonstra todo o otimismo e expectativa de um adulto que "reinicia" sua escolarização, relembrando os auxílios recebidos, os professores que o inspiraram. No entanto, relembra também, as experiências escolares marcadas por uma certa falta de "investimento" em relação a sua aprendizagem, apresentadas pelo aluno de três formas: a) Falta de adaptação temporal; b) de conteúdo e c) no processo avaliativo. 
a) Falta de adaptação temporal:

[...] os professores ficavam no quadro escrevendo, escrevendo. Ai eu dizia:Não apaga professor! Ele apagava, tinha que copiar do colega. Passava dever de casa pra responder no livro. Eu fazia! Ele dava o visto. (Relato de JC-quando indagado sobre o que aprendeu na escola).

JC relata que alguns professores não eram atentos às suas necessidades $\mathrm{e}$ demonstravam pouca importância se ele era capaz de acompanhar sua turma. Quando o aluno descreve como era seu cotidiano na escola, compreendo que eram necessários ajustes quanto ao seu tempo para concluir as atividades do quadro.

O professor, então, na postura de mediador da construção de conhecimentos, deve se preocupar com quem aprende, como aprende, com o porquê de estar trabalhando determinado conhecimento e, sobretudo, com a reflexão constante sobre o que está sendo discutido, dando abertura para a manifestação dos posicionamentos e ideias, contrárias à sua ou não (LEITE, 2003).

Entendo que é necessário que o docente identifique no contexto educacional se o aluno que apresente alguma deficiência ou não, compreende e participa de todas as atividades, se seu desenvolvimento é satisfatório, qual o ritmo de sua aprendizagem diante dos mais diversos conteúdos curriculares, sobre a motivação na realização das atividades e principalmente se necessita de tempo adicional para realização das mesmas.

No caso dos alunos com Deficiência Intelectual, a preocupação com adequação do tempo deve ser maior, já que o êxito da educação inclusiva dependerá, em grande medida, da oferta de uma rede de apoio à escola, através do trabalho de orientação, assessoria e acompanhamento do processo de inclusão (OLIVEIRA; LEITE, 2007).

\section{b) Falta de adaptação/flexibilização de conteúdo}

[...] "Não sabia fazer, perguntava pro professor, mas ele não me ensinava, e eu não ia aprender, era pesado mesmo, tinha que pensar, até os normais achavam pesado". (Relato de JC-grifo meu)

Identifico na memória do estudante uma certa indiferença do docente e posteriormente do próprio aluno, na forma como ele descreve sua aprendizagem. JC parece não ter sido muito estimulado no contato com os conteúdos oferecidos pela escola. Conforme pontua o 


\section{Revista Triângulo}

documento Educação Inclusiva: Atendimento Educacional Especializado para a Deficiência Mental, o aluno com deficiência intelectual deveria se diferenciar dos demais em termos de aprendizagem dos conteúdos escolares, pois, "trata-se de barreiras referentes à maneira de lidar com o saber em geral, o que reflete preponderantemente na construção do conhecimento escolar" (BRASIL, 2006, p. 17-18). O aluno com deficiência intelectual desafia a escola regular na sua finalidade de ensinar, de levá-lo a aprender o conteúdo curricular, construindo o conhecimento, no entanto, esses alunos aprendem de uma forma diferenciada, que nem sempre corresponde, com o que a escola espera.

JC por apresentar deficiência intelectual relata muitas dificuldades na aprendizagem dos conteúdos curriculares, no entanto, a maioria dos alunos com ou sem deficiência apresentavam a mesma dificuldade, principalmente no segundo segmento do ensino fundamental e ensino médio. Entretanto, o estigma de inferioridade sentido pelo aluno, talvez o impedisse de aprender mais do que a própria dificuldade nos conteúdos curriculares, conforme o registro a seguir:

[...] Era matéria pesada, era raiz quadrada, baixar não sei o que, isso é muito pesado pra mim (Relato de JC) (grifo meu)

O relato de JC traz dois elementos subjacentes: o primeiro vinculado a própria representação de incapacidade em função da sua deficiência; e o segundo é a critica a falta de acesso aos conhecimentos escolares, que vai ao encontro do que anuncio na seção 3, ao fazer um breve panorama das pesquisas sobre escolarização de pessoas com deficiência intelectual.

Outra diretriz legal, lançada no ano 2000 que visava auxiliar os professores, era o Projeto escola viva: Adaptações Curriculares de Grande Porte e Adaptações Curriculares de Pequeno Porte, do Ministério da Educação, que objetivava adaptações para garantir o acesso ao currículo, algumas ações que poderiam ser colocadas em prática para atender especificamente às necessidades do aluno com deficiência intelectual. Nesse caso, primeiramente devo considerar que o processo de apropriar o conhecimento tinha como base os conhecimentos que o aluno já possuía, ou seja, conhecimentos adquiridos de modo informal e, também, por processos formais anteriores de ensino e aprendizagem. Tais conhecimentos devem ser identificados pelo professor e utilizados como ponto de partida para a ampliação dos conceitos já adquiridos e a aquisição de novos conceitos (MEC/SEESP, 2000). 
A adaptação nos procedimentos didáticos e nas atividades de ensino-aprendizagem referiam-se a como ensinar os componentes curriculares, no que diz respeito às alterações que deveriam ser feitas nos métodos e técnicas para o ensino dos conteúdos previstos no currículo; à introdução de atividades complementares - utilizadas para reforçar o aprendizado; à introdução de atividades prévias e alternativas que pudessem prepará-lo para as próximas aprendizagens; à alteração do nível de abstração de uma atividade, oferecendo mais recursos visuais, auditivos, materiais manipulativos, etc.; à alteração do nível de complexidade de uma atividade e à adaptação de materiais (BRASIL, 1998; 2000).

Entendo que, dentre os muitos fatores a serem destacados para a efetivação da educação inclusiva, o currículo escolar é apontado como instrumento essencial para atender às especificidades dos alunos. Assim sendo, faz-se necessário ocorrer um constante ajustamento do currículo, desenvolvido junto as necessidades do aluno com deficiência intelectual, principalmente no ato do planejamento ressaltando as situações mais individualizadas.

\section{c) Avaliação}

[...] As provas era dificil, tinha professor que passava prova de marcar, o outro só de escrever, sempre tinha prova. Tinha trabalho também, mas pra passar valia a prova. (Relato de JC)

As provas foram consideradas uma das preocupações de JC, já que constituía o principal instrumento para atribuição de nota, seus relatos remetem sempre a muitas dificuldades e incertezas em relação aos aspectos avaliativos.

O reflexo das memórias leva a uma certa imprecisão sobre o aspecto da avaliação de JC e da falta de diversidade de instrumentos avaliativos. A avaliação dos alunos com deficiência, é citado como um dos principais fatores que inviabilizam a concretização da inclusão como afirma Pletsch (2013), associada a outras dificuldades.De maneira geral, a prática avaliativa ocorreu na trajetória do aluno, consoante ao desenvolvimento do medo da reprovação, não muito diferente do que ocorre com os alunos que não apresentam deficiência. O medo da reprovação, revela uma avaliação que por vezes, não é utilizada como instrumento capaz de compreender os avanços e os limites existentes no decorrer da caminhada dos alunos com ou sem deficiência.

Contudo, sobre os relatos de JC direcionados as práticas deficitárias da escola e de 
alguns professores, devo considerar que as demarcações temporais de sua escolarização, em meados de 2000, virada do século, evidenciam que o processo formativo dos professores voltado para as políticas inclusivas, se faz num contexto de mudanças e rupturas referentes à formação do professor, os cursos de formação de professores, ainda eram (e não quero afirmar que não sejam mais) marcados pela escassez de diretrizes sobre a ideia de incluir.

É importante considerar que ao analisar a escola de JC e seus processos de escolarização, deve-se permitir diferentes olhares, pois, sem que se dê conta, podemos nos ater apenas para um aspecto dessa múltipla realidade (e esta não é a intenção), já que, compreendo que esta escola vai sendo marcada por variações que remetem a impossibilidade de defini-la como escola que inclui ou excluí. Em síntese, a escola teve um papel importante como instituição formal, responsável por colaborar na construção do conhecimento adquirido por JC, também, não se nega que as experiências sociais, boas ou ruins, podem ser ressignificadas e contribuir, a posteriori, em aprendizagens para o indivíduo. Daí a importância dessas relações na vida dessas pessoas, principalmente na vida das pessoas com deficiência.

Por fim, descrever sobre uma trajetória tornou-se tarefa complexa, o trajeto que se vai de um lugar ao outro. Nesse percurso JC passa por momentos diversificados, complexos, cheios de percalços, desafios, entre outros inúmeros aspectos subjetivos e objetivos. Nesses relatos, corri o risco de esquecer algo, omitir alguma informação, passar despercebido de outra, não analisar de forma correta elementos presentes nesta trajetória, mas elenquei os que foram mais relevantes ao objeto de pesquisa.

\section{CONSIDERAÇÕES FINAIS}

No contexto geral da trajetória de escolarização observada, o objetivo foi o de analisar como se constituiu a trajetória de escolarização de um aluno com Deficiência Intelectual que concluiu a Educação Básica no Estado do Pará, procurei compreender como este estudante transitou por paradigmas, ora integrativos, ora inclusivos, até a conclusão de sua escolarização básica. 
Ouvir JC, se constituiu um dos encantos da pesquisa, já que a opção por privilegiar sua escuta, possibilitou-me um novo olhar sobre os processos de escolarização e para a compreensão da inclusão de alunos com deficiência intelectual. Diante do cenário de pesquisas sobre deficiência/escolarização/inclusão que expõem denuncismo, considero que este trabalho não almeja definir a escola como inclusiva ou não inclusiva. No entanto, levar a reflexão para como se constitui a escolarização de um aluno com Deficiência Intelectual que concluiu a Educação Básica no Estado do Pará, refletindo sobre a emergência de "novos" processos de escolarização, ou seja, aceitar os alunos com deficiência da forma como são, heterogêneos.

As memórias escolares mostram o quanto a organização da escola foi e continua sendo inadequada às necessidades dos alunos com deficiência intelectual. A partir dessa incursão depreende-se que as relações estabelecidas com a escola cumpriam uma "simulação do acompanhamento das atividades" criando a falsa impressão de que o aluno ao ouvir ou copiar do quadro estava aprendendo o conteúdo apresentado conforme os demais.

Neste contexto, questiono a pouca contribuição da escola no processo de ensinoaprendizagem e sua abordagem tradicional ao identificar as dificuldades do aluno e não intervir para seu desenvolvimento, pelo contrário, apenas classificá-lo, visando recolocá-lo em outro modelo educacional, sem questionar a necessidade de mudança da escola.

Durante sua escuta, ampliei a compreensão sobre a relevância das instituições especializadas, ao depreender que durante sua trajetória, ingressar na educação especial pareceu difícil, no entanto, posteriormente o estudante se identificou com esse modelo educacional, demonstrando que essas instituições podem ser pensadas como "centros de referência" para as escolas regulares.

A incursão pela trajetória de JC, trouxe argumentos para construir a ideia de que o objetivo da escola vai além da contribuição no desenvolvimento de capacidades cognitivas, sobretudo deve (ou pelo menos deveria) contribuir para potencializar todas as capacidades do ser humano. Enquanto os aspectos cognitivos se constituírem o "único" benefício da escola, os alunos com deficiência intelectual estarão em desvantagens durante a escolarização.

A escolarização de JC, durante boa parte dos 26 (vinte e seis anos) que levou para concluir a escola básica, girou em torno de sua limitação ou incapacidade, já que as suas potencialidades e aptidões em raras ocasiões foram levadas em conta. 
Por fim, durante a construção deste texto, a ideia que surgiu é a de que, durante as últimas décadas, fizemos (e continuamos fazendo) o que denominei de "inclusão culposa", ou seja, uma analogia ao crime culposo do direito (é aquele no qual não existe a intenção de matar), já na educação, podemos presumir que a "inclusão culposa" é aquela na qual não existe a intenção de excluir, mas, é uma escolarização marcada por momentos em que ocorrem a banalização/desresponsabilização do corpo docente, além do acesso a um conhecimento escolar empobrecido, destituído de sentido, deslocado e fragmentado, essas são práticas que remetem a uma culpa "inconsciente", uma conduta sem intenção de produzir o efeito negativo, porém, não podemos negar que é resultado de uma negligência e deixa marcas consideráveis na própria forma como os alunos com deficiência se percebem enquanto sujeitos, muitas práticas das quais JC apresentou demonstram uma "inclusão culposa", ou seja, entender como se dão essas práticas, e tentar neutralizá-las, é o desafio de todos que defendem uma escola inclusiva.

\section{REFERÊNCIAS}

AIMI, D. R. S.; TAMBORIL, M. I. B. . Breve discussão sobre o atendimento educacional especializado para estudantes com deficiência intelectual. In: Seminário de Psicologia - SEP, 2011, Porto Velho. Pesquisas em Educação e em Saúde, 2011. p. 113-121.

ANTUNES, Katiuscia C. Vargas. História de Vida de alunos com deficiência intelectual: percurso escolar e a constituição do sujeito / Katiuscia C. Vargas Antunes. - 2012. $154 \mathrm{f}$. Tese (Doutorado) - Universidade do Estado do Rio de Janeiro. Faculdade de Educação.

BAPTISTA, Cláudio Roberto (org.). Inclusão e escolarização: múltiplas perspectivas. 2. ed.-Porto Alegre: Mediação, 2015.

BRASIL. Governo do Estado do Paraná. Diretrizes Curriculares da Educação Especial para a construção de Currículos Inclusivos. Secretaria de Estado de Educação. SEED, Curitiba, 2006.

BRASIL. Lei $N^{\circ}$ 9394, de 20 de dezembro de 1996. Estabelece as diretrizes e bases da educação nacional.

Disponível

em:

<http://www.planalto.gov.br/ccivil_03/LEIS/19394.htm>. Acesso em 01 abril 2016.

BUENO, J. G. S.; MENDES, G. M. L.; SANTOS, R. A. Deficiência e escolarização: novas perspectivas de análise. Araraquara, SP: Junqueira \& Marin; Brasília: CAPES, p.43-66, 2008. 
CASTANHEIRA, A.O. Deixa que eu falo: A inclusão sob a ótica do estudante com Deficiência Intelectual. Rio de Janeiro, 2014.

CRESWELL, John W. Projeto de Pesquisa: método qualitativo, quantitativo e misto. 2. ed. Porto Alegre: Artmed, 2007.

FANTACINI, R. A. F; DIAS, T. R. S. Professores do Atendimento Educacional Especializado e a Organização do Ensino para o Aluno com Deficiência Intelectual. Rev. Bras. Ed. Esp., Marília, v. 21, n. 1, p. 57-74, Jan.-Mar., 2015.

HALBWACHS, M. A memória coletiva. Trad. de Laurent Léon Schaffter. São Paulo, Vértice/Revista dos Tribunais, 1990. Tradução de: La Mémorie collective.

LANGHI, R.; NARDI, R. Interpretando reflexões de futuros professores de física sobre sua prática profissional durante a formação inicial: a busca pela construção da autonomia docente. Revista Investigações em Ensino de Ciências, v. 16, n. 3, p. 403-424, 2011.

LEITE, L. P. A intervenção reflexiva como instrumento de formação continuada do educador: um estudo em classe especial. 2003. 212 f. Tese (Doutorado em Educação) Faculdade de Filosofia e Ciências, Universidade Estadual Paulista, Marília, 2003.

OLIVEIRA, A.A.S.; LEITE, L.P. Construção de um sistema educacional inclusivo: um desafio político-pedagógico. Revista Ensaio: Avaliação e Políticas Públicas em Educação. Vol. 15, fascículo 57, Cesgranrio/RJ, 2007.

PLETSCH, Márcia Denise (Org.). Estratégias educacionais diferenciadas para alunos com necessidades especiais. Rio de Janeiro: Eduerj, 2013, p. 17-32.

PLETSCH, M. D; OLIVEIRA, M. C. P. de; ARAUJO, D. F. Considerações sobre a escolarização de crianças e jovens com deficiência intelectual. Perspectiva em Diálogo: Rev. Educ. e Soc., Naviraí, v. 2, n. 3, p. 39-49, Jan.-Jun., 2015. Disponível em Home page: http://www.seer.ufms.br/index.php/persdia/index.

PLETSCH; ARAÚJO; LIMA. Experiências de formação continuada de professores: possibilidades para efetivar a inclusão escolar de alunos com Deficiência Intelectual. Rev. Periferia: Educação, cultura e comunicação. v.9 n.1 Jan.-Jun., 2017.

SANTOS, Teresa Cristina Coelho dos. Educação Inclusiva: práticas de professores frente à deficiência intelectual / Teresa Cristina Coelho dos Santos. - Natal, RN, 2012. 